\title{
SOLU-SALVARSAN
}

\section{TOXICOLOGICAL AND THERAPEUTIC TESTS MADE ON BEHALF OF THE \\ THERAPEUTIC TRIALS COMMITTEE OF THE MEDICAL RESEARCH COUNCIL}

\author{
Reported by L. W. HARRISON
}

Solu-Salvarsan was submitted to the Therapeutic Trials Committee in 1933 for investigation prior to application being made for a licence to import it into Great Britain. It is not on sale in this country but is used in other parts of the Empire and in various European and South American countries, where the following account of an investigation of its properties which has been carried out in London may be of interest.

According to the description furnished by its makers, I. G. Farben-Industrie, when it was first submitted to the Therapeutic Trials Committee, the preparation is a Io per cent. solution of Sodium 3:4 diacetyl-amino-4oxy-arseno-benzol-2 glycolate. Since then the solution has been modified in a few particulars (personal communications) but, judging by the leaflets supplied with it now, the compound itself remains as just described.

As the arsenical content of the dried compound is 20 per cent., the recommended dosage for men, 4 to 6 c.c. corresponds in this respect to 0.4 to $0.6 \mathrm{gm}$. neoarsphenamine. Its advantages are stated to be that it is stable, ready for intramuscular or intravenous injection when drawn from the ampoule and well tolerated when injected intramuscularly.

A. test of the remedy which was carried out at the National Institute for Medical Research in October, I933, before it was submitted to clinical trial here showed that, weight for weight, its toxicity for mice when given intravenously was somewhat less than that of the average good specimen of neoarsphenamine. Thus the dose of neoarsphenamine of accepted standard quality needed 
to produce a 50 per cent. mortality is about $0.5 \mathrm{mg}$. per $\mathrm{gm}$. and the dose of the sample of Solu-salvarsan submitted for test which was needed to produce this effect when given intravenously to a large number of mice was calculated to be between 0.5 and 0.75 per gm.

In view of what follows it is of interest that in the same experiment a dose of $0.75 \mathrm{mg}$. per gm. mouse given intravenously killed 3 out of Io mice ; I of I mg. per gm., 8 out of Io ; and I of I.5 mg. per gm., 9 out of Io.

In a retest of the same batch carried out a year later $0.75 \mathrm{mg}$. per gm. killed only I out of Io mice, so that under ordinary conditions of storage the sample did not become more toxic.

The official German directions of $26 / 3 / 35$ for testing the toxicity of Solu-salvarsan state that I c.c. of a $I / 40$ solution per $20 \mathrm{gm}$. body weight is to be given to mice subcutaneously, and not more than 30 per cent. of the animals should die; to each of another set of mice is to be given I c.c. of a I/30 solution per 20 gm., and not more than 66 per cent. should die. Three rats are to be injected with 2.5 c.c. of the ro per cent. solution per $\mathrm{kg}$. body weight, and 3 others with 2 c.c. per kg., and the injections must cause no local reaction. Two rabbits must be injected subcutaneously in the abdominal wall with 2 c.c. of the solution per $\mathrm{kg}$. and any local reaction following the injections must have disappeared four days later.

It is not possible to compare the performance of the sample tested at the National Institute for Medical Research with the requirements of the official test because the injections here were intravenous. It may, however, be of interest to note that I c.c. of I/40 solution per $20 \mathrm{gm}$. prescribed in the above official test corresponds to $\mathrm{I} \cdot 25 \mathrm{mg}$. per $\mathrm{gm}$. and that I $\mathrm{mg}$. per gm. administered intravenously at the National Institute killed 8 out of ro mice. The descriptive leaflet in English which is issued by the makers states that a dose of $20 \mathrm{mg}$. subcutaneously or one of Io $\mathrm{mg}$. intravenously is well tolerated by mice. Assuming that this means per $20 \mathrm{gm}$. weight as in the official directions, the well-tolerated dose administered intravenously would be $0.5 \mathrm{mg}$. per gm.; at this dose the submitted sample killed 4 out of Io mice and I out of Io on the retest a year later.

As regards therapeutic activity, the sample submitted 
in I933 proved to be about one-third as active against $T$. equiperdum in mice as is a good sample of neoarsphenamine. Thus 0.075 and 0.10 $\mathrm{mg}$. Solu-salvarsan per $\mathrm{gm}$. weight respectively had the same effect as 0.025 and $0.03 \mathrm{mg}$. per $\mathrm{gm}$. of a standard sample of neoarsphenamine.

Judging by the protocol of the official German test, I c.c. of a I/75 dilution of the standard Io per cent. solution per $20 \mathrm{gm}$. weight administered to 3 mice clears their blood of trypanosomes (forty fields) for a minimum of ten days. This dose seems to be approximately $0.066 \mathrm{mg}$. per gm. mouse.

In the tests here of the submitted sample it required $\mathrm{o} \cdot \mathrm{Io} \mathrm{mg}$. per gm. weight to produce this effect so that, so far as it is possible to judge from protocols based on somewhat different standards of trypanosome infection the curative dose in the German test appears to be rather smaller than that of the sample tested here.

The German instructions require that 25 doses of 5 c.c. administered intramuscularly in two State hospitals shall have been followed by no ill-effect in a period of four weeks ; presumably these injections are given to 25 different patients.

As regards the ability of Solu-salvarsan to cause disappearance of $S$. pallida from the discharge of early lesions in 1934, following the above tests at the National Institute for Medical Research the product was administered to a number of patients with early syphilis and was found inferior to any good brand of neoarsphenamine. Whereas a dose of $0.45 \mathrm{gm}$. neoarsphenamine given intravenously causes $S$. pallida to disappear from the juice of early lesions in the very great majority of cases within twenty-four hours, 6 c.c. Solu-salvarsan given by the same route failed in 3 out of 5 cases, and when given deep subcutaneously, failed in 5 out of 5 cases ; in 4 of these patients who returned $S$. pallida was still easily demonstrable seventy-two hours after the injection.

The doses then administered appeared to be well tolerated, and the trial was continued on 5 cases of early syphilis but had to be suspended because dermatitis had occurred in 3, jaundice in 2, and severe local pain in 2 . These effects had been observed after totals of two to four injections of 4 to 5 c.c. Retests of the sample for toxicity in animals which were carried out at the National 


\section{BRITISH JOURNAL OF VENEREAL DISEASES}

Institute for Medical Research disclosed, as already mentioned, no evidence that the Solu-salvarsan used in the above cases had deteriorated.

At this time I was told that a modification had been made in the solvent of Solu-salvarsan, and a trial of the modified preparation was started in February, I935. Intravenously, a dose of 6 c.c. caused disappearance of $S$. pallida from the discharge of early lesions within twenty-four hours in 7 out of Io cases, so that in this respect the remedy still compared very unfavourably with neoarsphenamine. In 5 late cases of syphilis no untoward result, either local or general, resulted from a course of intramuscular injections, but later in 3 early cases treated with total doses of 35, 4I and I I c.c. respectively, dermatitis occurred in the first and third.

The experience up to date, therefore, suggested that the advantages of convenience and of comparative freedom from discomfort after intramuscular or deep subcutaneous injection of Solu-salvarsan were more than offset by the higher incidence of toxic effects, particularly dermatitis, following its administration, and by its lower therapeutic effect as judged by its ability to cause the disappearance of $S$. pallida from the discharge of early lesions.

In view of these results the investigation was suspended. It was resumed in 1938 as a result of a report by Lieut.Colonel E. T. Burke to the Therapeutic Trials Committees' Sub-committee on Anti-syphilitic Remedies, in which he detailed the results of treatment by Solu-salvarsan of 5 sero-negative primary cases of syphilis, 3 sero-positive primary and one secondary.

In this trial, except in the first case, the remedy was given intramuscularly twice a week over a period of six weeks, during which no other treatment was given; the first case had three injections $(4,5$ and 5 c.c.) in the first week. In the 5 sero-negative primary cases, $S$. pallida disappeared from the lesion juice on the first, fourth, eighth, first and twelfth days respectively following the injection and in the remaining cases on the second. He judged in this trial that, in respect of therapeutic power, the preparation had proved equal to neoarsphenamine in 2 cases but inferior in 7 . The injections appear to have caused no pain, and no definite toxic effects were recorded. Colonel Burke thought that better results 206 
might be obtained without toxic effects by giving Solusalvarsan " thrice weekly, in dosage of 5,5 and 5 c.c., or 6,4 and 6 c.c."

The further investigation indicated by this report was undertaken by the following members of the Subcommittee on Anti-syphilitic Remedies mentioned above.

Dr. T. Anwyl-Davies, St. Thomas's Hospital.

Lieut.-Colonel E. T. Burke, The Whitechapel Clinic.

Mr. James Kemble, The London Lock Hospital.

Dr. G. L. N. McElligott, St. Mary's Hospital.

Dr. V. E. Lloyd, Guy's Hospital.

It was agreed that early cases of syphilis should be treated with three doses of 5 c.c. each per week for six weeks, no other remedy being given.

The results reported were as follows :-

DR. ANWYL-DAVIES.-Six cases of primary syphilis (2 sero-negative) treated with total dosages of I5, 20, $20,70,75$ and 90 c.c. respectively. S. pallida disappeared from the lesion juice two days after the injection in 3 cases and in three, three and six days in the remainder. In the 3 cases treated with 70 to 90 c.c. 2 remained seropositive, and in the third the Wassermann reaction became negative and the Kahn doubtful. Arsenical dermatitis occurred in 3 cases, I (generalised) after the fourth injection, and 2 (chiefly affecting the arms) after the third and fifteenth injections respectively.

Colonel Burke.-Five primary cases (I sero-negative). Disappearance of $S$. pallida in twenty-four hours was recorded in 3 cases, in forty-eight hours in 2 , and between the second and sixth days in I. Behaviour of serum reactions was recorded in 3 cases. In the first, Wassermann and Sigma reactions remained negative, and the Kahn after becoming positive reverted to negative by the twenty-first day, after 30 c.c. In the second the Wassermann and Sigma reactions were negative by the nineteenth day but the Kahn remained positive until the thirty-second day, after 70 c.c. In the third all serum reactions remained positive after 90 c.c. had been given. Dermatitis occurred in 3 cases after 70, I 5 and 75 c.c. respectively, the second of these cases also having jaundice.

DR. V. E. LLOYD.-Four cases of sero-negative primary syphilis treated with eighteen, nine, two and two injec- 
tions of 5 c.c. respectively; the smaller numbers of injections were due to default in I case and untoward effects in 2.

$S$. pallida were found on the sixth day following the injection in I case, on the fourth day in $I$, and at the thirtieth hour in I ; the observation on the fourth case is that $S$. pallida were not found forty-eight hours after the first injection.

Healing of chancres occurred in seven, ten and eighteen days in 3 cases ; in the fourth, as the chancre showed no sign of healing and had become painful during the first four days, Novostab was substituted for Solu-salvarsan and the chancre promptly healed.

The Wassermann reaction remained negative in 3 cases, and became positive by the twelfth day in $I$. The Kahn reaction became temporarily positive in 3 cases.

Two of the patients showed no sign of intolerance after eighteen and nine injections respectively, I had moderately severe pain in the buttock for twenty-four hours after an injection and I had a herpetic eruption on the left side of the face with œdema of face and lips following the second injection.

Mr. Kemble.-Two cases treated. In I, S. pallida were found in the chancre juice until the sixth day; in the other they were absent on the fourth day. The chancres healed on the thirteenth and seventeenth days respectively. One case initially sero-positive did not become negative until the end of six weeks after eighteen injections.

In the other case a very severe dermatitis developed on the ninth day after the fourth injection, the whole body being affected, with œdema of the face, temperature of I02.4 and pulse of IIO. Initially sero-positive, this patient's Wassermann and Kahn remained positive on the thirty-third day.

DR. McElligotT.-Three cases were treated with eight, nine and eighteen injections respectively. $S$. pallida were certainly present in the chancre juice of 2 after twenty-four hours; none was found at the end of forty-eight hours in any of the cases.

The chancres healed in thirteen, fifteen and seventeen days. The serum reactions, originally negative in 2 cases and doubtful in I, were negative in all at the end of the treatment. No toxic reactions were recorded. 


\section{SUMMARY}

All the observers who collaborated in this investigation agreed in finding that the therapeutic power of Solusalvarsan, weight for weight, was quite distinctly less than that of neoarsphenamine. This was shown in the persistence of $S$. pallida in chancre juice after administration of the remedy and in the slower healing of lesions. It might have been foreseen from the results of the trypanocidal tests.

Toxic reactions were unduly frequent. The number of cases treated with two or more doses of Solu-salvarsan by the six observers, whose results are described above, was 42 , and dermatitis was recorded in 12 , jaundice in 3 and herpes of the face in I; also severe pain at the site of injection was reported in 3 cases. The details do not support any suggestion that the toxic effects were due to excessive dosage, as the dermatitis occurred after less than five injections in 8 of the dermatitis cases, and all those in which jaundice occurred, as also the herpetic eruption of the face, followed the second injection.

\section{EXPERIENCE OF OTHER WORKERS}

A study of the literature leaves the strong impression that Solu-salvarsan has been found by many other workers to be more prone to cause dermatitis than is neoarsphenamine. It is unnecessary to quote the literature in any detail and only papers in a few publications will be mentioned.

In 1933 the Dermatologische Wochenschrift published the replies of six syphilologists to a questionnaire it had issued to the following effect. "What is your experience of the use, therapeutic value and tolerability of the dissolved-and-ready-for-use salvarsan preparation 'Solusalvarsan'?" Summaries of their replies are as follows :-

H. G. Bode thought that in respect of its effect on serum reactions, Solu-salvarsan was slower than neosalvarsan. In 30 per cent. of his cases he had seen side effects in the form of early or late exanthems; although most of these subsided quickly, he saw in this increased incidence of dermatoses a disadvantage of the preparation as compared with others. 


\section{BRITISH JOURNAL OF VENEREAL DISEASES}

G. Ensbruner used Solu-salvarsan in combination with mercurial inunctions, giving 3 c.c. twice weekly to a total average dose of 40 c.c. He saw no difference between it and Neosalvarsan in respect of its effect on clinical signs and the disappearance of $S$. pallida, but he thought it less active than Neosalvarsan in respect of its effect on serum reactions. Benign exanthems of the nine-day type occurred, but he could not be sure that they were more frequent than after Neosalvarsan, because at the time the observations were made exanthems were rather frequent in his hospital after various salvarsan preparations.

A. Memmesheimer had treated ro primary and secondary cases with doses of 3 to 5 c.c. twice weekly to a total of 40 to 50 c.c., bismogenol being given simultaneously. The clinical effect was reported as good but the side effects amounted to one rise of temperature and two exanthems, and this relatively high incidence of toxic effects led the author to cease using the preparation.

G. Riehl, Jun., had used the preparation only in cases which had reacted to Neosalvarsan with severe vasomotor symptoms in spite of the various precautions to prevent this side effect. None of these patients had been upset in this way by Solu-salvarsan. In order to avoid cumulative effects, he gave not more than 6 c.c. Solusalvarsan a week. He reported that soon after starting to use the preparation he had seen in some cases slight exanthems and in one case a slight salvarsan dermatitis ; these were attributed to over-dosage. He saw in this tendency to cause dermatitis and the simplicity of administration of Solu-salvarsan a danger from its use by relatively unskilled physicians.

G. Scherber had treated 75 cases in doses of 2 to 5 c.c. to totals of 30 to 50 c.c. He had noted the disappearance of outward signs such as sclerosis, papules, etc., after administration of 25 to 30 c.c., and the serum reaction was usually negative after 50 c.c. In 7 of the 75 cases the patients had previously been unable to tolerate Neosalvarsan because of severe angio-neurotic symptoms, but Solu-salvarsan had been tolerated. Salvarsan erythemata were more frequent than under Neosalvarsan, the incidence being 5 cases in 75 treated. All are reported as having been slight and disappearing in eight to fourteen days. 


\section{SOLU-SALVARSAN}

W. Schönfeld reported that the cases which he had treated were chiefly those unsuitable for intravenous injection and were therefore few in number. He considered that the clinical signs and serum reactions ciisappeared more slowly under Solu-salvarsan than under treatment with other salvarsan preparations. Commenting on the tendency of the preparation to evoke skin reactions, he said that its future would depend on this factor.

Fasal and Konrad (I937), in reporting 2 fatal cases of dermatitis following treatment with Solu-salvarsan referred to the above-mentioned answers to the questionnaire by Dermatologische Wochenschrift, and quoted a number of other reports to the same effect. Thus, Kogoj (1933), had seen a relatively large number of toxic exanthems (5 in 39 cases), and later (1935) reported a death in a forty-six-year-old woman after 23 c.c. of the remedy injected intramuscularly. Hammerschmidt reported a reduction of incidence of dermatitis after Solu-salvarsan from $\mathrm{I} 2 \cdot 8$ to $6 \cdot \mathrm{I}$ per cent. by care to prevent sensitisation of the skin through deposit of any of the solution in it when making an injection, Fasal (I933) in a review of the salvarsan dermatitis which had been seen in Kerl's clinic, Vienna, from I928-32, reported a death following a total dosage of I.IO $\mathrm{gm}$. Solusalvarsan, with some Bismogenol. It should be mentioned, however, that previously this patient had had an urticarial swelling of the face after an initial dose cf $0 \cdot 3 \mathrm{gm}$. Neosalvarsan. Fulöp saw dermatitis in 6 cases treated with Solu-salvarsan intravenously but the dermatitis had disappeared under continuance of the course with intramuscular injections. Riehl, Jun. (I935), saw with the increased use of Solu-salvarsan by the intramuscular route a parallel increase of Solu-salvarsan dermatitis. It is only fair to mention that Fasal and Konrad quoted Kneževic as having seen no toxic effect of Solusalvarsan in 20 cases and Tonian none in 22 cases; also that Manecuta had reported well on the preparation.

Fasal and Konrad said that no dermatitis due to Solusalvarsan had occurred in their practice because they had always opposed the use of the intramuscular route, but they had an opportunity of seeing cases in other services and they had not always been light and benign. In the first of the 2 fatal cases which they reported the patient, 


\section{BRITISH JOURNAL OF VENEREAL DISEASES}

aged sixty-one, had received 40 c.c. from September to November, I935, 36 c.c. from January to April, I936, and 30 c.c. (in doses of 3 c.c.) from June to July, 1936. The dermatitis was generalised and very severe, and was complicated by an ulcerative enteritis which led to peritonitis.

In the second case the patient was aged fifty, and the dermatitis follows $I \times 4$ c.c., $4 \times 5$ c.c. and $2 \times 6$ c.c. ; after the fourth injection there had been severe itching. The dermatitis was generalised and there were ulcers on the vocal cords and sides of the tongue. At the autopsy there were found also numerous sub-pleural hæmorrhages.

The authors concluded with their personal view, that intramuscular injection of Solu-salvarsan is to be avoided in all cases.

\section{CONCLUSION}

Ample evidence has been given above to show that Solu-salvarsan is a preparation which has a weaker therapeutic action than Neoarsphenamine and a decidedly greater toxic action, particularly in respect of dermatitis. In the face of such important disadvantages it is difficult to see any indication for its use in the treatment of syphilis.

\section{REFERENCES}

Bode, H. G. : Dermat. Wschr., I933, 97, I036.

ENSBRUNER, G. : Ibid., I933, I037.

FASAL, P., and KonRad, J. : Med. Klin., I937, 33, 1360.

FülöP : Börgyógy Szemle 3, I934 (ref. Fasal and Konrad).

HAMmerschmidT: Zdravn. Vestnika, I933 (ref. Fasal and Konrad). KNEŽEvić : Sprski, I934, Arch. No. II (ref. Fasal and Konrad).

KogoJ, Fr. : Derm. Wschr., I933, 96, 507.

KoGoJ, Fr. : Ztbl. Hautkrkh., I935, 50, 253 (ref. Fasal and Konrad). Manecuta : Cluj. Med., I934 (ref. Fasal and Konrad).

Memmesheimer, A. : Dermat. Wschr., I933, 97, I038.

RIEHL, G., Jun. : Ibid., I933, I038.

SCHERBER, G. : Ibid., I933, I038.

SCHÖNFELD, W. : Ibid., I933, IO39.

Tonian: Sovet Vestn. Ven. i. Derm., I935, 4, 465 (ref. Fasal and Konrad). 